with an epidemic strain of multiresistant Salmonella typhimuriumDT104 in England and Wales. Commun. Dis. Rep. CDR Rev. 4:R130-R13.

Mention of trade names or commercial products in this article is solely for the purpose of providing specific information and does not imply recommendation or endorsement by the U.S. Department of Agriculture. Address correspondence to Dr. Steve A. Carlson, USDA-ARS, National Animal Disease Center, 2300 Dayton Rd., Box 70, Ames, IA 50010, USA.e-mail: scarlson@ nadc.ars.usda.gov

Received 12 July 2000; accepted 27 September 2000.

Timothy S. Frana and Steve A. Carlson ${ }^{1}$ Iowa State University College of Veterinary Medicine 'USDA, Agricultural Research Service

Ames, IA, USA

\section{Large-Scale Colony Screening and Insert Orientation Determination Using PCR}

BioTechniques 30:32-34 (January 2001)

Though many diagnostic PCR methods have been described, few techniques have been developed to rapidly and efficiently screen transformed bacterial colonies for plasmid presence (1). Unfortunately, PCR screening of a large number of colonies is time consuming and requires substantial amounts of polymerase and primers. In this report, we describe a two-step large-scale bacterial colony screening method that we have labeled "cracking PCR". Cracking PCR includes (i) size screening of cracked bacterial colonies (i.e., selecting lysed clones displaying a band similar to the expected recombinant size) in an agarose gel and (ii) PCR screening of gel-determined potential positives directly from the cracking buffer/colony mixture. This method offers several advantages. First, the initial use of conventional cracking methods permits many colonies to be screened quickly in agarose, rather than the several hours required for PCR am plification. Second, since only the apparent positive clones will be used as template in PCR, fewer reactions will be necessary, thus reducing time and cost requirements. Finally, cracking PCR serves to reconfirm the presence of positive recombinants. The initial cracking step assists to verify that a band present in the PCR amplification reaction is a true band, rather than an artifact resulting from contamination from another colony or an anomaly of the reaction.

Figure 1 illustrates a flowchart of the cracking PCR procedure. Bacterial colonies are lysed using a protocol based on a previously described method (2). This method has been significantly modified. Briefly, $1 \mathrm{~mm}^{2}$ of each colony is picked from a masterplate with a sterile toothpick and twisted in $50 \mu \mathrm{L}$ cracking buffer (in $200 \mathrm{~mL}$ : 50 $\mathrm{mM}$ Tris-HCl, $\mathrm{pH} 7.5,2 \mathrm{mM}$ EDTA, $1 \% \mathrm{SDS}, 27.4 \mathrm{~g}$ sucrose, $20 \mathrm{mg}$ bromophenol blue, and $20 \mathrm{mg}$ xylene cyanol) in $0.5-\mathrm{mL}$ microcentrifuge

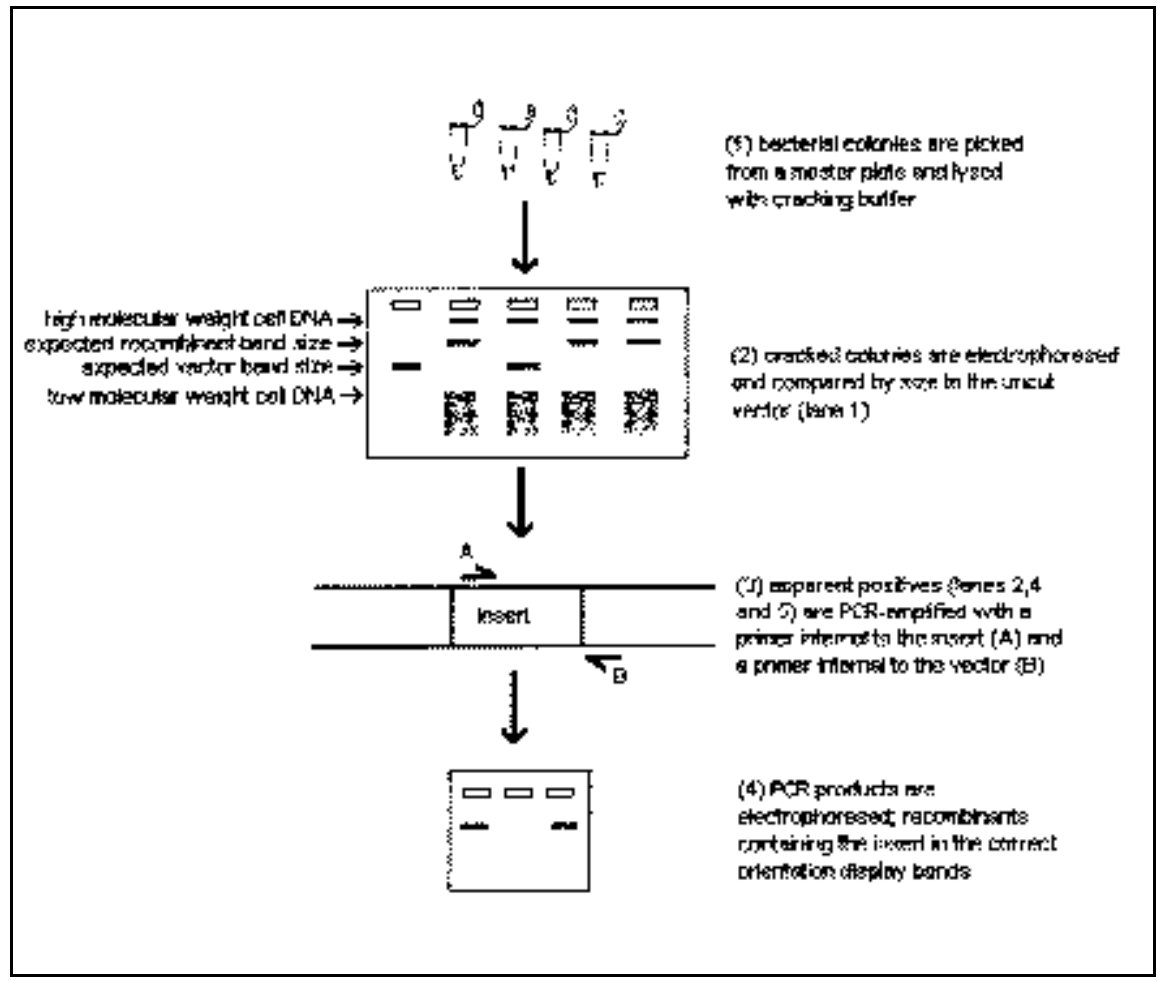

Figure 1. Flowchart of the cracking PCR method. 


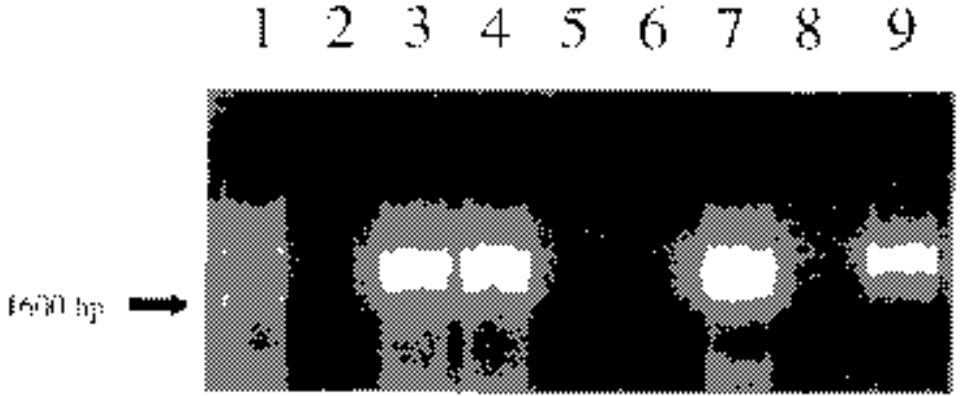

Figure 2. PCR products from a bacterial transformation (TOP10F strain) after performing the cracking PCR method. Lane 1 is a $1-\mathrm{kb} ~ \lambda$ ladder (Life Technologies). Products in lanes $2-5$ were am plified using one forward primer internal to the insert (GB5-3) and one reverse primer internal to the vector ( $3^{\prime}$ AOX1; Invitrogen, Carlsbad, CA, USA). Lane 2 is transformed pGAPZ $\alpha A$ (Invitrogen). Lanes 3 and 4 contain a 1928-bp fragment amplified from two different clones of transformed pGAPZ $\alpha$ A $\bullet$ GB53 [pGAPZ $\alpha A$ containing a glucocerebrosidase (EC 3.2.1.45.) insert] with the insert in the correct orientation. Lane 5 contains a 1932-bp fragment amplified from transformed pGAPZ $\alpha$ A $\bullet$ GB5-3 with the insert in the incorrect orientation. Products in lanes $6-8$ were all amplified using two reverse primers: one internal to the vector ( $\left.3^{\prime} \mathrm{AOX} 1\right)$, the other internal to the insert (GB2). Lane 6 is transformed pGAPZ $\alpha A \cdot G B 5-3$ with the insert in correctly. Lane 7 is pGAPZ $\alpha A \cdot G B 5-3$ with the insert in incorrectly. Lane 8 is the negative control. Lane 9 is the positive control of transformed pGAPZ $\alpha \cdot$ AB $5-3$ confirmed by sequence analysis, containing a 1928-bp segment amplified with primers GB5-3 and 3'AOX1.

tubes. The tubes are vortex mixed briefly, incubated at room temperature for $20 \mathrm{~min}$, and centrifuged at $13000 \times$ $g$ for $15 \mathrm{~min}$. Then, $45 \mu \mathrm{L}$ of the mixture are loaded into a $0.7 \%$ agarose gel with ethidium bromide and electrophoresed at $70 \mathrm{~V}$ for $45 \mathrm{~min}$. After the gel is photographed, it is analyzed for evidence of possible positive recombinants (i.e., a band of similar size to the expected recombinant size). From all the potential positive clones, $0.5 \mu \mathrm{L}$ of the buffer/colony mixture is used as template for PCR amplification in $0.2-\mathrm{mL}$ thin-walled microcentrifuge tubes (Gordon Technologies, Mississauga, ON, Canada) containing $5 \mu \mathrm{L}$ $10 \times$ PCR Buffer (Life Technologies, Rockville, MD, USA), $8 \mu \mathrm{L} 25 \mathrm{mM}$ $\mathrm{MgCl}_{2}, 5 \mu \mathrm{L} 2.5 \mathrm{mM}$ dNTPs, $4 \mu \mathrm{L} 5$ $\mu \mathrm{M}$ each of the specific primers (com bination of insert forward primer GB53: 5'-ACTCGAATTCTTCATCTAAG GACCCTGAGG-3' and vector reverse primer 3'AOX1: 5'-GCAAATGGCATTCTGACATCCTC-3' to test for correct orientation, or combination of insert reverse primer GB2: 5'-GCGGG AATTCTTTAATGCCCAGGCTGAG CC-3' and 3'AOX1 to test for incorrect orientation), and 2 U Taq DNA Poly- merase (Life Technologies) in a total volume of $50 \mu \mathrm{L}$. The PCR program used in Figure 2 was an initial denaturation at $94^{\circ} \mathrm{C}$ for $2.5 \mathrm{~min}$, followed by 30 cycles of $94^{\circ} \mathrm{C}$ for $1 \mathrm{~min}, 57^{\circ} \mathrm{C}$ for $1.5 \mathrm{~min}$, and $72^{\circ} \mathrm{C}$ for $1.5 \mathrm{~min}$, with a final extension at $72^{\circ} \mathrm{C}$ for $7 \mathrm{~min}$. The products were electrophoresed in a $1.0 \%$ agarose gel.

It is important to note that inclusion of a primer to screen for the insert in the incorrect orientation is not necessary in this cracking PCR method, unless one wants to confirm a clone as a control for later expressions. The use of a primer internal to the vector coupled with an opposite primer internal to the insert will amplify only those clones with inserts in the correct orientation. For those clones in which no band appeared in the subsequent electrophoresis, it can be assumed that either the insert was in the incorrect orientation or that no insert was actually present.

In conclusion, this cracking PCR method permits rapid large-scale screening of bacterial colonies and the determination of insert orientation without vector purification. This technique can easily be applied to screen diverse bacterial colonies for different types of vec- tors containing various inserts, as long as one internal vector primer and one internal insert primer with compatible annealing temperatures are available.

\section{REFERENCES}

1.Gussow, D. and T. Clackson. 1989. Direct clone characterization from plaques and colonies by the polymerase chain reaction. Nucleic Acids Res. 17:4000.

2.Sambrook, J., E.F. Fritsch, and T. Maniatis. 1989. Molecular Cloning: A Laboratory Manual, Vol. 1. CSH Laboratory Press, Cold Spring Harbor, NY.

This research was supported by a Natural Sciences and Engineering Research Council grant no. 600-16-1 to Dr. Francis Choy and a Natural Sciences and Engineering Research Council PSG-A Scholarship to Tessa Campbell. The $p G A P Z \alpha A \bullet G B 5-3$ recombinant vectors with inserts in the correct and incorrect orientations were generously donated by Camille Wolf (Department of Biology, University of Victoria). The GB5-3 primer was donated by Graham Sinclair (Department of Biology, University of Victoria). Address correspondence to Tessa N. Campbell, Department of Biology, University of Victoria, Box 3020 STN CSC, Victoria, BC V8W $3 N 5$ Canada. e-mail: tessac@uvic.ca

Received 10 May 2000; accepted 10 October 2000.

\section{Tessa N. Campbell and \\ Francis Y.M. Choy \\ University of Victoria \\ Victoria, BC, Canada}

